\title{
Magnetic and vibrational properties of high-entropy alloys
}

\author{
M. S. Lucas, ${ }^{1,2, a)}$ L. Mauger, ${ }^{3}$ J. A. Muñoz, ${ }^{3}$ Yuming Xiao, ${ }^{4}$ A. O. Sheets, ${ }^{1}$ S. L. Semiatin, ${ }^{1}$ \\ J. Horwath, ${ }^{1}$ and Z. Turgut ${ }^{1}$ \\ ${ }^{1}$ Air Force Research Laboratory, Wright-Patterson AFB, Ohio 45433, USA \\ ${ }^{2}$ UTC Inc., 1270 North Fairfield Road, Dayton, Ohio 45432, USA \\ ${ }^{3}$ California Institute of Technology, W. M. Keck Laboratory 138-78, Pasadena, California 91 125, USA \\ ${ }^{4} \mathrm{HPCAT}$, Geophysical Laboratory, Carnegie Institute of Washington, Argonne, Illinois 60439, USA
}

(Presented 18 November 2010; received 1 October 2010; accepted 21 October 2010; published online 21 March 2011)

\begin{abstract}
The magnetic properties of high-entropy alloys based on equimolar $\mathrm{FeCoCrNi}$ were investigated using vibrating sample magnetometry to determine their usefulness in high-temperature magnetic applications. Nuclear resonant inelastic x-ray scattering measurements were performed to evaluate the vibrational entropy of the ${ }^{57} \mathrm{Fe}$ atoms and to infer chemical order. The configurational and vibrational entropy of alloying are discussed as they apply to these high-entropy alloys. () 2011 American Institute of Physics. [doi:10.1063/1.3538936]
\end{abstract}

\section{INTRODUCTION}

High-entropy alloys (HEAs) are multicomponent alloys where the atomic fraction of each of the elements is nearly equal. ${ }^{1}$ These materials have been studied for their high hardness, resistance to wear, and corrosion resistance. A recent report by Chou et al. ${ }^{2}$ indicated that $\mathrm{FeCoCrNiAl}_{x}$ alloys exhibit minima in the thermal expansion between 500 and $600^{\circ} \mathrm{C}$. The authors attributed this to the Curie temperature, which would make these alloys useful for applications requiring magnetic materials at elevated temperatures. Direct measurements of the magnetization by Zhang $e t$ al. ${ }^{3}$ have shown the HEA FeCoCrNiAlCu to have a Curie temperature of $\sim 70^{\circ} \mathrm{C}$ after a $2 \mathrm{~h}$ heat treatment. The research presented in this article was performed to verify these results and to assess the usefulness of such materials for magnetic applications at elevated temperatures.

At moderate temperatures, the vibrational entropy $S_{\mathrm{ph}}$ dominates the Gibbs free energy, $G=H-T S$, where $H$ is the enthalpy and $S$ is the entropy. As a function of temperature and composition, the alloy phase or combination of phases with the lowest Gibbs free energy is the equilibrium state. Therefore, even though the vibrational entropy may be large in magnitude, what matters is the difference in vibrational entropy between phases. Differences in $S_{\mathrm{ph}}$ between phases can be small, as is the case for the ordering transition in $\mathrm{FeCo}$ alloys ${ }^{4}$ or quite large, as is the case for alloying vanadium with platinum. ${ }^{5}$ The magnitude of the configurational entropy $S_{\text {conf }}$ is small compared to $S_{\mathrm{ph}}$ at moderate temperatures. However, changes in $S_{\text {conf }}$ between phases can often be large, especially in cases of chemical unmixing (spinodal decomposition) and chemical ordering.

Recently, the claim that the high mixing entropy of HEAs stabilizes the random solid solution and suppresses the formation of intermetallic compounds, an idea originally proposed by Yeh et al., ${ }^{1}$ has come into question. Wang et al.

\footnotetext{
${ }^{\text {a) }}$ Author to whom correspondence should be addressed. Electronic mail: matthew.steven.lucas@gmail.com.
}

showed that ordered $\mathrm{NiAl}$ forms in the alloy $\mathrm{FeCoCrNiAlCu},{ }^{6}$ which was cited as the main cause for strengthening in the alloy. Indeed, superlattice reflections indicative of chemical ordering have been observed in the $\mathrm{x}$-ray diffraction patterns presented in several studies. ${ }^{1,3,7,8}$ Knowledge of how phonons behave in a material may also be used to infer chemical ordering, ${ }^{9}$ which is one of the goals of this work.

\section{EXPERIMENTS}

Alloys of stoichiometric ${ }^{57} \mathrm{FeNi},{ }^{57} \mathrm{FeCoCrNi},{ }^{57} \mathrm{FeCoCr}-$ $\mathrm{NiPd},{ }^{57} \mathrm{FeCoCrNiPd} 2,{ }^{57} \mathrm{FeCoCrNiAl}_{2}$, and ${ }^{57} \mathrm{FeCoCrNiAlCu}$ were prepared by arc melting under an argon atmosphere using $96.06 \%$ enriched ${ }^{57} \mathrm{Fe}$ and elemental $\mathrm{Co}, \mathrm{Cr}, \mathrm{Ni}, \mathrm{Pd}, \mathrm{Al}$, and $\mathrm{Cu}$ of purity $99.99 \%$ or greater. The as-cast buttons were cold rolled to thicknesses of 100-250 $\mu \mathrm{m}$, with the exception of the Al-containing alloys, which were too brittle to roll. $\mathrm{X}$-ray diffraction (XRD) patterns were acquired at room temperature for all samples. Electron microprobe measurements confirmed the compositions to be accurate to 0.5 at. $\%$. The magnetization as a function of temperature for the as-cast samples was measured with a vibrating sample magnetometer from room temperature to $1000^{\circ} \mathrm{C}$ and upon cooling under an applied field of $0.05 \mathrm{~T}$. The saturation magnetization was also acquired before and after the high-temperature moment measurements at an applied field of $2 \mathrm{~T}$.

Nuclear resonant inelastic $\mathrm{x}$-ray scattering $\left(\right.$ NRIXS) ${ }^{10-12}$ was performed at beamline 16ID-D at the Advanced Photon Source (APS) of the Argonne National Laboratory. The experimental procedures were the same as those reported for a recent experiment on $\mathrm{FeCo}$ alloys. ${ }^{4}$ All measurements were performed at room temperature. The monochromator resolution function was measured in situ using a single APD in the forward direction. The FWHM was $\sim 2.2 \mathrm{meV}$. The NRIXS data reduction was performed with the software PHOENIX. ${ }^{13}$

\section{RESULTS AND DISCUSSION}

The x-ray diffraction patterns showed ${ }^{57} \mathrm{FeNi},{ }^{57} \mathrm{FeCoCrNi}$, ${ }^{57} \mathrm{FeCoCrNiPd}$, and ${ }^{57} \mathrm{FeCoCrNiPd}_{2}$ to all be single phase 
TABLE I. Measured lattice parameter $a$, Curie temperature $T_{C}$, saturation magnetization $M_{s}$, entropy for the Fe atoms $S_{\mathrm{ph}}^{\mathrm{Fe}}$, and average phonon energy $\langle E\rangle$ of high-entropy alloys. All values are reported at room temperature, with the exception of $T_{C}$. Values in parentheses are for the alloys after cooling from $1000^{\circ} \mathrm{C}$. The configurational entropy of mixing for a fully disordered random solid solution $S_{\text {conf }}^{\text {rs }}$ is shown.

\begin{tabular}{|c|c|c|c|c|c|c|c|}
\hline Sample & $a_{\mathrm{bcc}} \pm 0.005(\AA)$ & $a_{\mathrm{fcc}} \pm 0.005(\AA)$ & $T_{C} \pm 3(\mathrm{C})$ & $M_{s} \pm 2(\mathrm{emu} / \mathrm{g})$ & $\langle E\rangle \pm 0.1(\mathrm{meV})$ & $S_{\mathrm{ph}}^{\mathrm{Fe}} \pm 0.01\left(k_{B} / \mathrm{Fe}\right.$-atom $)$ & $S_{\text {conf }}^{\text {rss }}\left(k_{B} /\right.$ atom $)$ \\
\hline $\mathrm{FeCoCrNiAlCu}$ & 2.8693 & 3.6260 & & $41(16)$ & 24.9 & 3.40 & 1.792 \\
\hline $\mathrm{FeCoCrNiAl}_{2}$ & 2.8867 & & $157(268)$ & $13(18)$ & 26.2 & 3.25 & 1.561 \\
\hline $\mathrm{FeCoCrNiPd}_{2}$ & & 3.7068 & 230 & 34 & 22.6 & 3.66 & 1.561 \\
\hline $\mathrm{FeCoCrNiPd}$ & & 3.6473 & 167 & 33 & 22.8 & 3.65 & 1.609 \\
\hline $\mathrm{FeCoCrNi}$ & & 3.5643 & Paramagnetic & 3 & 24.3 & 3.46 & 1.386 \\
\hline $\mathrm{FeNi}$ & & 3.5868 & 517 & 129 & 24.1 & 3.50 & 0.693 \\
\hline $\mathrm{Fe}$ & 2.8665 & & 773 & 218 & 26.6 & 3.18 & 0 \\
\hline
\end{tabular}

with the face-centered cubic (fcc) crystal structure. Alloying $\mathrm{FeCoCrNi}$ with Pd resulted in an increase of the lattice parameter, as expected for the larger Pd atom. The alloy ${ }^{57} \mathrm{FeCoCr}$ $\mathrm{NiAl}_{2}$ was single-phase body-centered cubic (bcc). The ${ }^{57} \mathrm{FeCoCrNiAlCu}$ sample was two phase (fcc and bcc), with a fcc phase fraction of $\sim 80 \%$ from the relative $x$-ray intensities. In both of the Al-containing alloys, (100) superlattice peaks were observed for the bcc phase. These peaks are indicative of chemical ordering, particularly the formation of an Al-rich sublattice, and are consistent with the measurements of Tung, ${ }^{8}$ Tong, ${ }^{7}$ Zhang, ${ }^{3}$ and $\mathrm{Yeh}^{1}$ for $\mathrm{FeCoCrNiAlCu}$. The values of the fcc and bcc lattice parameters in Table I for FeCoCrNiAlCu are also consistent with these reports. For $\mathrm{FeCoCrNi}$ and $\mathrm{FeCoCrNiAl}$, the x-ray diffraction patterns and lattice parameters are consistent with the report by Chou. ${ }^{2}$

The results of the magnetization measurements are presented in Fig. 1 and Table I. The saturation magnetizations at room temperature are low compared to the value for pure $\mathrm{Fe}$ of $218 \mathrm{emu} / \mathrm{g}$. The Curie temperatures of the HEAs are also low compared to pure $\mathrm{Fe}\left(773^{\circ} \mathrm{C}\right)$ and pure $\mathrm{Co}$ $\left(1115^{\circ} \mathrm{C}\right)$. The low saturation magnetizations and Curie temperatures make these alloys poor candidates for soft magnetic applications at high temperature. This is largely to be expected, since the ferromagnetic elements $\mathrm{Fe}, \mathrm{Ni}$, and $\mathrm{Co}$

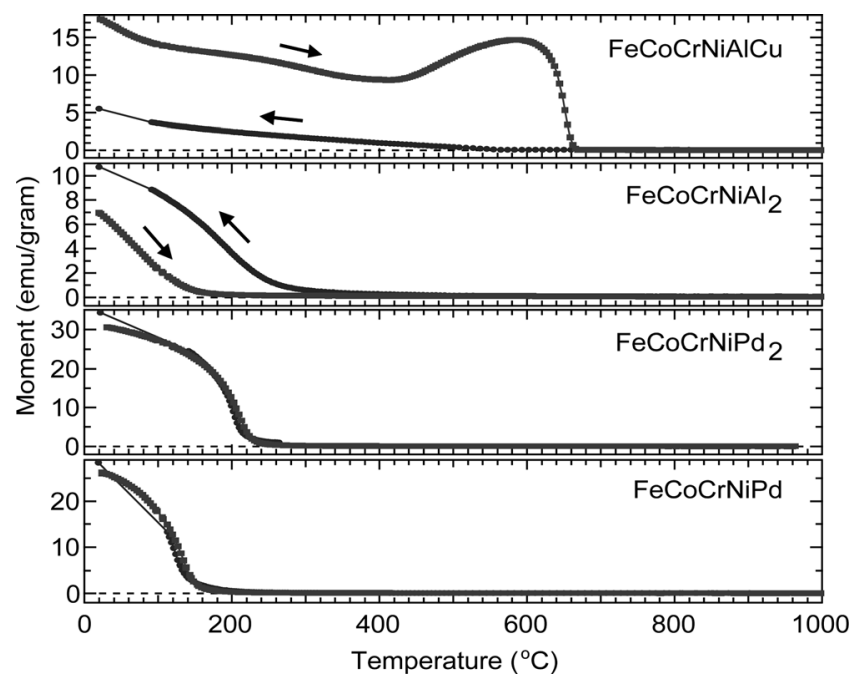

FIG. 1. Temperature dependence of magnetic moment (applied field of $0.05 \mathrm{~T}$ ) for high-entropy alloys upon heating $(\rightarrow)$ and cooling $(\leftarrow)$. are alloyed with antiferromagnetic $\mathrm{Cr}$ in the HEAs. The alloy $\mathrm{FeCoCrNi}$ was paramagnetic at room temperature. Alloying with Pd increases the magnetic moment and Curie temperature in the fcc phase. Control of the Curie temperature with $\mathrm{Pd}$ additions may make these alloys useful for magnetic refrigeration applications near room temperature.

The measured Curie temperature for $\mathrm{FeCoCrNiAl}_{2}$ is much lower than those inferred by Chou from thermal expansion minima for $\mathrm{FeCoCrNiAl}_{x}$ alloys. ${ }^{2}$ These minima are very similar to those reported by Yokoyama for equiatomic $\mathrm{FeCo}$ (Ref. 14) after slow cooling from $800^{\circ} \mathrm{C}$. This behavior, termed the " $550^{\circ} \mathrm{C}$ anomaly," has also been observed in a number of other properties and attributed to chemical reordering, although a complete explanation has not been provided to date.

The $\mathrm{FeCoCrNiAlCu}$ alloy lost its magnetic signature at $\sim 650^{\circ} \mathrm{C}$. This is attributed to a phase transformation, not a Curie temperature, and is consistent with the phase diagram presented by Tong ${ }^{7}$ showing spinodal decomposition at this temperature. The room-temperature saturation magnetizations for $\mathrm{FeCoCrNiAlCu}$ are also consistent with those reported by Zhang, ${ }^{3}$ where a decrease of $M_{s}$ was observed after a $2 \mathrm{~h} 1000^{\circ} \mathrm{C}$ heat treatment.

The results of the NRIXS measurements are presented in Fig. 2. These curves are the ${ }^{57} \mathrm{Fe}$ phonon partial density of states (Fe-PDOS). The total DOS is the concentration weighted sum of the PDOS of each atom species in the alloy, and is required for calculating thermodynamic quantities such as the vibrational entropy or phonon contribution to the heat capacity. The first moment $\langle E\rangle$ and vibrational entropy ${ }^{15,16}$ from the Fe-PDOS are presented in Table I.

The results show that the Fe-PDOS for $\mathrm{FeCoCrNi}$ is similar to that of equiatomic $\mathrm{FeNi}$, indicating similar interatomic forces for the Fe atom in both alloys. This may be expected, since the alloys have the same fcc crystal structure and similar molecular weights. Alloying with Pd causes a softening (decrease in phonon energies) of the Fe modes, consistent with a larger average mass. The increased lattice parameter induced by the addition of $\mathrm{Pd}$ is also expected to decrease the average phonon energy according to the quasiharmonic model. ${ }^{17}$ This softening results in an increase in the vibrational entropy of $0.20 k_{B} / \mathrm{Fe}$-atom from $\mathrm{FeCoCrNi}$ to $\mathrm{FeCoCrNiPd}$ at $300 \mathrm{~K}$. This is likely to be a lower bound on the total vibrational entropy change, since the $\mathrm{Co}, \mathrm{Cr}$, and 




FIG. 2. ${ }^{57} \mathrm{Fe}$ phonon partial density of states curves from NRIXS spectra at $300 \mathrm{~K}$. Curves are normalized to unity and offset by integer multiples of $0.04 \mathrm{meV}^{-1}$. The line without error bars is the curve for FeCoCrNi.

$\mathrm{Ni}$ atoms (having masses similar to Fe) are likely to have a similar change in vibrational entropy, while the $\mathrm{Pd}$ atoms (having much larger mass than Fe) should have a larger vibrational entropy. In comparison, the resulting change in configurational entropy from alloying (assuming a random solid solution) is $0.22 k_{B}$ /atom. In general, the change in configurational entropy upon alloying decreases upon increasing the number of elements in equimolar HEAs.

The $\langle E\rangle$ of the alloy $\mathrm{FeCoCrNiAl} 2$ is much larger than the fcc alloys, but similar to the values for bcc Fe and FeCo of 26.6 meV. $^{4}$ High-energy optical modes are observed between 40 and $50 \mathrm{meV}$. These modes are indicative of the formation of an Al-rich sublattice, ${ }^{9}$ which is consistent with the observation of superlattice reflections in the x-ray diffraction patterns. The high-energy modes are not observed in the $\mathrm{FeCoCrNiAlCu}$ alloy. Wang et al. showed that NiAl intermetallics form in this alloy, ${ }^{6}$ accounting for the observed superlattice reflections in the XRD patterns. The chemical analysis presented by Tong et $a l^{7}$ showed the interdenrite regions to be $\mathrm{Cu}, \mathrm{Al}$, and $\mathrm{Ni}$ rich, so that the $\mathrm{Fe}$ atoms may not be present in the ordered phase. This would explain the observation of superlattice peaks in the XRD patterns and the lack of optical modes in the Fe-PDOS.

\section{CONCLUSIONS}

High-entropy alloys based on $\mathrm{FeCoCrNi}$ were found to be poor candidates for soft magnetic applications, especially at elevated temperatures. Palladium additions increased the saturation magnetization and Curie temperature. The change in configurational entropy upon alloying with $\mathrm{Pd}$ is similar in magnitude to the change in the vibrational entropy. Evidence of chemical ordering in $\mathrm{FeCoCrNiAl}$, was found in both the $\mathrm{x}$-ray diffraction patterns and the inelastic $\mathrm{x}$-ray results indicating the formation of Fe-aluminides. However, ordering in $\mathrm{FeCoCrNiAlCu}$ was observed only in the x-ray diffraction patterns, indicating the formation of Ni-alumindes.

\section{ACKNOWLEDGMENTS}

Portions of this work were performed at HPCAT (Sector 16), Advanced Photon Source (APS), Argonne National Laboratory. HPCAT is supported by CIW, CDAC, UNLV, and LLNL through funding from DOE-NNSA, DOE-BES, and NSF. Use of the APS was supported by DOE-BES, under Contract No. DE-AC02-06CH11357.

${ }^{1}$ J.-W. Yeh, S.-K. Chen, S.-J. Lin, J.-Y. Gan, T.-S. Chin, T.-T. Shun, C.-H. Tsau, and S.-Y. Chang, Adv. Eng. Mater. 6, 299 (2004).

${ }^{2}$ H.-P. Chou, Y.-S. Chang, S.-K. Chen, and J.-W. Yeh, Mater. Sci. Eng., B 163, 184 (2009).

${ }^{3}$ K. B. Zhang, Z. Y. Fu, J. Y. Zhang, J. Shi, W. M. Wang, H. Wang, Y. C. Wang, and Q. J. Zhang, J. Alloys Compd. 502, 295 (2010).

${ }^{4}$ M. S. Lucas, J. A. Muñoz, L. Mauger, C. W. Li, A. O. Sheets, Z. Turgut, J. Horwath, D. L. Abernathy, M. B. Stone, O. Delaire, Y. Xiao, and B. Fultz, J. Appl. Phys. 108, 023519 (2010).

${ }^{5}$ O. Delaire, T. Swan-Wood, and B. Fultz, Phys. Rev. Lett. 93, 185704 (2004).

${ }^{6}$ Y. P. Wang, B. S. Li, and H. Z. Fu, Adv. Eng. Mater. 11, 641 (2009).

${ }^{7}$ C.-J. Tong, Y.-L. Chen, S.-K. Chen, J.-W. Yeh, T.-T. Shun, C.-H. Tsau, S.-J. Lin, and S.-Y. Chang, Metall. Mater. Trans. A 36A, 881 (2005).

${ }^{8}$ C.-C. Tung, J.-W. Yeh, T.-t Shun, S.-K. Chen, Y.-S. Huang, and H.-C. Chen, Mater. Lett. 61, 1 (2007).

${ }^{9}$ L. Anthony, L. J. Nagel, J. K. Okamoto, and B. Fultz, Phys. Rev. Lett. 73, 3034 (1994).

${ }^{10}$ E. E. Alp, W. Sturhahn, T. S. Toellner, J. Zhao, M. Hu, and D. E. Brown, Hyperfine Interact. 144-145, 3 (2002).

${ }^{11}$ M. Seto, Y. Yoda, S. Kikuta, X. W. Zhang, and M. Ando, Phys. Rev. Lett. 74, 3828 (1995).

${ }^{12}$ W. Sturhahn, T. S. Toellner, E. E. Alp, X. Zhang, M. Ando, Y. Yoda, S. Kikuta, M. Seto, C. W. Kimball, and B. Dabrowski, Phys. Rev. Lett. 74, 3832 (1995).

${ }^{13}$ W. Sturhahn, Hyperfine Interact. 125, 149 (2000)

${ }^{14}$ T. Yokoyama, J. Jpn. Inst. Met. 21, 321 (1957).

${ }^{15}$ D. C. Wallace, Statistical Physics of Crystals and Liquids (World Scientific, Singapore, 2002).

${ }^{16}$ B. Fultz, Prog. Mater. Sci. 55, 247 (2010).

${ }^{17}$ G. Grimvall, Thermophysical Properties of Materials (North Holland, Amsterdam, 1999). 